\title{
Pigmented Squamous Cell Carcinoma: Is the Reported Prevalence Real?
}

\author{
Paola Corneli ${ }^{1}$, Elvira Moscarella ${ }^{2}$, Eugenia V. Di Brizzi², Andrea Ronchi ${ }^{3}$, \\ Iris Zalaudek ${ }^{1}$, Roberto Alfano ${ }^{4}$, Giuseppe Argenziano ${ }^{2}$
}

\author{
1 Dermatology Unit, University of Trieste, Trieste, Italy \\ 2 Dermatology Unit, University of Campania, Naples, Italy \\ 3 Anatomo-pathology Unit, University of Campania, Naples, Italy \\ 4 Department of Anesthesiology Surgery and Emergency, University of Campania, Naples, Italy
}

Key words: squamous cell carcinoma, pigmented squamous cell carcinoma, prevalence, dermoscopy, blue pigmentation

Citation: Corneli P, Moscarella E, Di Brizzi EV, Ronchi A, Zalaudek I, Alfano R, Argenziano G. Pigmented squamous cell carcinoma: is the reported prevalence real? Dermatol Pract Concept. 2019;9(2):150-151. DOI: https://doi.org/10.5826/dpc.0902a13

Accepted: August 30, 2018; Published: April 30, 2019

Copyright: $@ 2019$ Corneli et al. This is an open-access article distributed under the terms of the Creative Commons Attribution License, which permits unrestricted use, distribution, and reproduction in any medium, provided the original author and source are credited.

Funding: None.

Competing interests: The authors have no conflicts of interest to disclose.

Authorship: All authors have contributed significantly to this publication.

Corresponding author: Giuseppe Argenziano, MD, Dermatology Unit, University of Campania, Nuovo Policlinico (edificio 9C), Via Pansini 5, 80131 Naples, Italy. Email: g.argenziano@gmail.com

\section{Introduction}

Pigmented squamous cell carcinoma (PSCC) is a rare variant of squamous cell carcinoma (SCC), generally described in oral mucosa, conjunctiva and cornea, but only rarely found on the skin. Histopathologically, it is characterized by a proliferation of atypical keratinocytes associated with nonneoplastic dendritic melanocytes and melanophages in the surrounding stroma [1]. Clinically and dermoscopically PSCC diagnosis is very difficult because of overlapping features with benign and malignant lesions, including basal cell carcinoma (BCC), melanoma, pigmented actinic keratosis, and seborrheic keratosis. Only 22 cases of PSCC have been reported in the literature (Table 1).

We searched our image database from 2011 to 2018 and found 899 histopathologically diagnosed SCCs, with only 3 of them being pigmented (prevalence of $0.33 \%$ of all SCCs).
We present 1 of these 3 cases, showing clinical and dermoscopic characteristics of pigmented BCC.

\section{Case Presentation}

A 77-year-old white man presented with a $12-\mathrm{mm}$ lesion of the chest, which had been noticed 1 year before. Clinically, the lesion appeared as a pigmented nodule with central ulceration (Figure 1A). Dermoscopically, it showed blue areas at the periphery and white polymorphous vessels surrounding a central hyperkeratotic area (Figure 1B). Histopathological examination showed epidermis with hyperkeratosis and full-thickness cellular atypias. In some fields, solid nests were evident in the superficial dermis, constituted by atypical cells with abundant, slightly eosinophilic cytoplasms and intercellular bridges. The dermis was diffusely infiltrated by a dense lichenoid lymphocytic population. A final diagno- 
sis of infiltrating $(0.9-\mathrm{mm})$ SCC with G2 differentiation was rendered (Figure $1, \mathrm{C}$ and $\mathrm{D})$.

\section{Conclusions}

Dermoscopy alone does not allow differentiating PSCC from other pigmented skin lesions. The present case highlights how overlapping features with pigmented BCC are possible in PSCC. The majority of keratinizing tumors, and SCC in particular, are nonpigmented. Dermoscopic examination of these tumors generally reveals the presence of hairpin or atypical vessels, often surrounded by a whitish halo associated with the keratinizing process. Our case showed blue areas and linear polymorphous vessels surrounding a central hyperkeratotic area. Zalaudek et al described a similar case of PSCC with a bluish diffuse pigmentation with central ulceration [2]. Others reported cases of PSCC with overlapping dermoscopic features of melanocytic lesions with radial brown streaks and globules.

The real prevalence of PSCC is unclear, with the English literature reporting an incidence of about $0.01 \%$ to $7 \%$ of all SCCs, whereas the nonEnglish literature describes an incidence of approximately $25 \%$ [1]. The rate we found in our population, $0.33 \%$ of all SCCs, is between these 2 values. These variability in incidence rates may be due to factors related to the skin type of the population included. However, further studies are needed to support this hypothesis.

\section{References}

1. Satter EK. Pigmented squamous cell carcinoma. Am J Dermatopathol. 2007;29(5):486-489.

2. Zalaudek I, Citarella L, Soyer HP, Hofmann-Wellenhof R, Argenziano G. Dermoscopy features of pigmented squamous cell carcinoma: a case report. Dermatol Surg. 2004;30(4 Pt I):539-540.
Table 1. All Described Cases of PSCC in the Literature With Associated Author

\begin{tabular}{|l|l|c|}
\hline \multicolumn{1}{|c|}{ Author, Year } & Site & $\begin{array}{c}\text { No. of Cases } \\
\text { Described }\end{array}$ \\
\hline Becker, 1934 & Not stated & 3 \\
\hline Kossard, 1997 & Ear & 1 \\
\hline Jurado, 1998 & Frontotemporal and nose & 2 \\
\hline Matsubo, 1999 & Scrotum & 1 \\
\hline Kamiya, 1999 & External auditory canal & 1 \\
\hline Morgan, 2000 & $\begin{array}{l}\text { Right helix, left temple, left eyebrow, } \\
\text { right cheek, right temple }\end{array}$ & 5 \\
\hline Chapman, 2000 & Middle forehead & 1 \\
\hline Terada, 2003 & Right cheek & 1 \\
\hline Zalaudek, 2004 & Chest & 1 \\
\hline Satter, 2007 & Left cheek & 1 \\
\hline Chung, 2015 & Back & 1 \\
\hline de Giorgi, 2009 & Upper lip & 1 \\
\hline Verdú-Amorós, 2016 & Head & 1 \\
\hline Savoia, 2013 & Nose & $\mathbf{2 2}$ \\
\hline Namiki, 2015 & Cheek & \\
\hline Total & & 1 \\
\hline
\end{tabular}

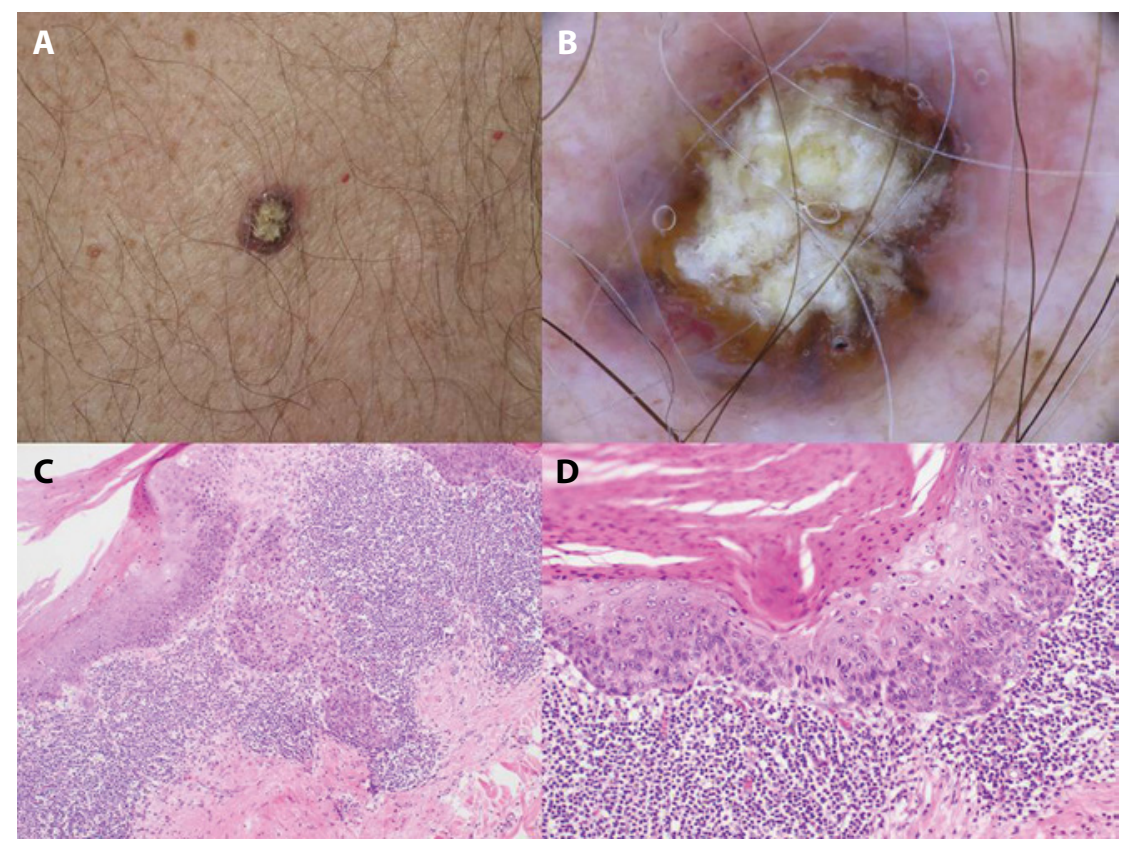

Figure 1. (A) Clinical image of a nodular lesion on the right chest of a 77-year-old man. (B) Dermoscopic examination shows blue areas and polymorphous vessels surrounding a central hyperkeratotic area. (C) Histopathological examination $(\times 20)$ shows hyperkeratosis and full-thickness cellular atypias. In some fields, some solid nests were evident in the superficial dermis, constituted by atypical cells with abundant slightly eosinophilic cytoplasms and intercellular bridges. The dermis was diffusely infiltrated by a dense lichenoid lymphocytic population. (D) Higher magnification ( $\times 40$ ) of panel C. [Copyright: (92019 Corneli et al.] 